\title{
Determination of Microstructure of Polybutadiene by Decoupled PMR Spectra
}

\author{
Koichi Hatada, Yasuyuki Tanaka, ${ }^{*}$ Yoshio Terawaki, \\ and Hiroshi OKudA \\ Department of Chemistry, Faculty of Engineering Science, \\ Osaka University, Toyonaka, Osaka, Japan. \\ KEY WORDS Polybutadiene / PMR Spectra / Spin Decoupling / \\ Microstructure / cis-cis, cis-trans, trans-trans Linkages /
}

(Received June 6, 1973)

Several papers have been published concerning the determination of the microstructure of polybutadiene by $\mathrm{PMR}^{1}$ and ${ }^{13} \mathrm{C}-\mathrm{NMR}$ spectroscopy. ${ }^{2-5}$ By using the undecoupled PMR spectrum of polybutadiene the contents of 1,2 and 1,4 units can be measured, although the fractions of cis-1,4 and trans-1,4 units cannot be determined. ${ }^{1}$ On the other hand, the determination of the fractions of 1,2 , cis- 1,4 , and trans-1,4 structures can be done by ${ }^{13} \mathrm{C}-\mathrm{NMR}$ spectroscopy, but the peak separation corresponding to the cis-cis, cis-trans, and trans-trans linkages cannot be observed in the spectrum., In this work we were able to determine the fractions of cis-1,4 and trans-1,4 units as well as those of cis-cis, cis-trans, and trans-trans linkages in the UV-isomerized polybutadienes by using the spin-decoupling technique for PMR spectra.

Isomerization of polybutadiene was carried out in benzene at room temperature with a highpressure mercury lamp, using diphenyl disulfide as an initiator. ${ }^{6}$ cis-1,4-Polybutadiene was used as the starting material. The PMR spectra of the solution in $\mathrm{CDCl}_{3}$ was taken with a JEOL $100 \mathrm{MHz}$ spectrometer (JNM-MH-100) at $35^{\circ} \mathrm{C}$, using tetramethylsilane as an internal reference.

Undecoupled and decoupled PMR spectra of the polybutadienes are shown in Figure 1. In the undecoupled spectrum there were two signals at about 2.06 and $5.37 \mathrm{ppm}$, which correspond

* Department of Textiles and Polymer Science, Faculty of Technology, Tokyo University of Agriculture and Technology, Koganei, Tokyo, Japan. to methylene and olefinic methine protons respectively. The methine proton signal of isomerized polybutadiene split into two peaks at 5.37 and $5.41 \mathrm{ppm}$, when it was decoupled from the methylene protons. The methine protons of cis-1,4- and trans-1,4-polybutadienes showed

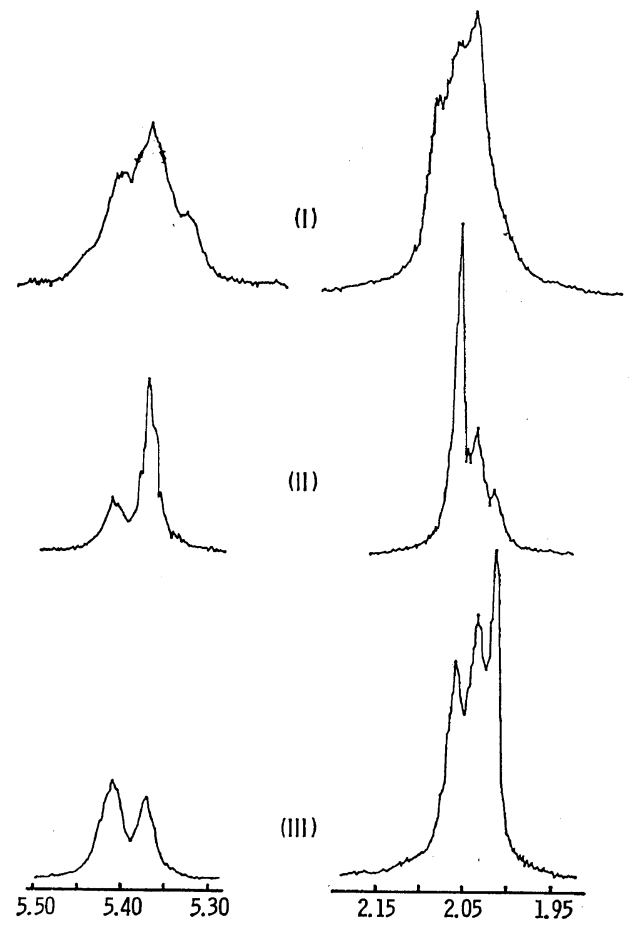

Figure 1. Undecoupled and decoupled PMR spectra of UV-isomerized polybutadienes: I, undecoupled spectra of polymer A, II and III, decoupled spectra of polymer A and polymer B respectively. 
K. Hatada, Y. Tanaka, Y. Terawaki, and H. OKuda

Table I. Microstructure of UV-isomerized polybutadiene

\begin{tabular}{cccccc}
\hline Sample & cis-1,4 & trans-1,4 & cis-cis & cis-trans & trans-trans \\
\hline \multirow{2}{*}{ A } & 74.6 & 25.4 & 53.5 & 38.6 & 7.9 \\
& $(73.6)^{\mathrm{a}}$ & $(26.4)^{\mathrm{a}}$ & $(55.7)^{\mathrm{b}}$ & $(37.9)^{\mathrm{b}}$ & $(6.5)^{\mathrm{b}}$ \\
$\mathrm{B}$ & 43.7 & 56.3 & 19.0 & 52.1 & 28.9 \\
& $(42.2)^{\mathrm{a}}$ & $(57.8)^{\mathrm{a}}$ & $(19.1)^{\mathrm{b}}$ & $(49.2)^{\mathrm{b}}$ & $(31.7)^{\mathrm{b}}$ \\
\hline
\end{tabular}

a Determined by ${ }^{13} \mathrm{C}-\mathrm{NMR}$ spectroscopy.

b Calculated value, assuming a random distribution of cis-1,4 and trans1,4 units.

sharp singlets at 5.38 and $5.40 \mathrm{ppm}$ respectively, when they were decoupled from the methylene protons. This clearly shows that the two peaks in the decoupled signal of the methine protons of isomerized polybutadiene correspond to cis1,4 and trans-1,4 units with decreasing magnetic field. By the intensity measurements of these two peaks with a Du Pont 301 Curve Resolver the contents of the cis-1,4 and trans-1,4 units could be determined. The results were in close agreement with those obtained by the ${ }^{13} \mathrm{C}-\mathrm{NMR}$ method, ${ }^{5}$ as shown in Table I.

On the other hand, the methylene proton signal decoupled from the methine proton split into three peaks at 2.06, 2.04, and $2.02 \mathrm{ppm}$. The methylene protons in cis-1,4-polybutadiene resonated at $2.07 \mathrm{ppm}$ and those in trans-1,4polymer at $2.01 \mathrm{ppm}$, when they were decoupled from the methine proton. This indicates that the three peaks can be assigned in order of increasing magnetic field to the methylene protons in the cis-cis, cis-trans (trans-cis), ${ }^{*}$ and trans-trans linkages. It has been found that in the isomerized polybutadiene cis-1,4 and trans1,4 units are distributed almost randomly along the chain., The fractions of cis-cis, cistrans, and trans-trans linkages expected for the

* In the cis-trans linkage there are two types of methylene protons, in cis-1,4 and trans-1,4 units. The result obtained here shows that the chemical shift between these two types of methylene protons is too small to be distinguished in the decoupled spectrum. random distribution were calculated from the fractions of cis-1,4 and trans-1,4 units and were compared with those obtained from the peak intensity in the decoupled methylene signal (Table I). A fairly close agreement was obtained, indicating the validity of the above assignment.

Acknowledgement. The authors are very grateful to Mr. M. Ikeyama of Japan Synthetic Rubber Co., for his help in the laboratory work, to Dr. N. Oguni of Osaka University for the use of Du Pont 301 Curve Resolver, and to Mrs. F. Yano for her clerical assistance in preparing this manuscript.

\section{REFERENCES}

1. Y. Tanaka, Y. Takeuchi, M. Kobayashi, and H. Tadokoro, J. Polym. Sci., Part A-2, 9, 43 (1971).

2. M. W. Duch and D. M. Grant, Macromolecules, 3, 175 (1970).

3. V. D. Moche1, J. Polym. Sci., Part A-1, 10, 1009 (1972).

4. Y. Alaki, T. Yoshimoto, M. Imanari, and M. Takeuchi, Kobunshi Kagaku (Chem. High Polymers), 29, 397 (1972).

5. Y. Tanaka and K. Hatada, Polymer Letters, to be published.

6. J. I. Cunneen, G. M. C. Higgins, and W. F. Watson, J. Polym. Sci., 40, 1 (1959).

7. M. Berger and D. J. Buckley, ibid., Part A, 1, 2945 (1963). 